\title{
An Empirical Study of Network-Based English Reading Teaching for Senior School Students*
}

\author{
ZHANG Lin, ZHOU Yin-feng \\ Linyi University, Linyi, China
}

\begin{abstract}
As is known to all, English reading is not only the main abilities to use English but also the main body in English exams. As an effective method to improve the students' ability of reading, English reading under the network environment begins to be used in the English teaching. This paper takes 60 students in grade one in high school as the research subjects, who are further divided into two groups: the experimental group and the control group. The students of the experimental group are taught under network environment. At the same time, the students of the control group are taught as usual. After 3 months' experiment the results show that the students' reading interest, speed, and performance in the experimental group are relatively higher than that of the control group. The research attempts to know whether high school students' English reading ability can be improved under network environment. We do hope that this paper can benefit English learners' reading ability in the future learning.
\end{abstract}

Keywords: network environment, teacher-student interactive model, English reading

\section{Introduction}

In the age of information and technology, computer and network not only brought revolutionary changes to people's life but also made great impact on language learning. What is more, with the unceasing progress of the globalization, the growing significance of English makes more and more people aware of English learning through Internet. Besides, considering the relatively limited teaching resources, a new teaching mode based on modern network technology is developing fast, so that English language teaching and learning will be free from the constraints of time or place to some extent, and enhance the ability of students' autonomous learning. That is why the author attempts to find a new way for the English reading teaching practice. This paper mainly aims to testify that network-based multimedia English teaching method.

\section{An Introduction to the Network-Based English Reading Teaching Model}

The high school English reading teaching model under the network environment is a new teaching method in English teaching. The model has five steps: (1) Importing background. The teacher will search some relevant reading materials on the Internet and then present them to the students before the class. (2) Reading speed training.

\footnotetext{
* This paper is supported by the project of Implementation of Network-Based Interactive Learning in Modern Distance Education approved by the Shandong Vocational Education Department.

ZHANG Lin, School of Foreign Languages, Linyi University.

ZHOU Yin-feng, associate professor, master, School of Foreign Languages, Linyi University.
} 
The students read the materials and are asked to finish the text reading within the predetermined time. (3) Vocabulary learning. Combined with text content, the teacher designs some vocabulary exercises to help students expand their vocabulary. (4) Reading comprehension training. By finding a topic sentence and reading comprehension tests to consolidate their knowledge and further improve their learning efficiency. (5) Communicating after class. All the students' reading methods and suggestion are uploaded in the Internet, so the teachers and students can leave a message on the message boards.

\section{Research Design}

\section{Research Question}

The experimental group is involved in the conducting of this online model, and the control group is taught under the environment of traditional teaching. The research aims at addressing the question: Whether senior school students' English reading ability can be improved under network environment.

\section{Research Subjects}

The research subjects are 60 students, who come from one Senior High School, in Linyi, Shandong Province. They have the same level in English reading and are random selected from Grade 1. There are 30 students in the experimental group and the others in the controlled group. During the experiment, students in the experimental group are taught under the network environment, while the other students in the control group learn in the traditional teaching model.

\section{Research Instruments}

Three instruments have been used in the study questionnaires, tests, and interviews. To test whether there is a significant distinguish between the two groups, two questionnaires were supposed to be given to the two groups: pre-questionnaire and post-questionnaire. Two tests were also given to the students: pre-test and post-test. In addition, interviews are put forward to know about the students' attitude toward the online model and the progress the subjects have made or not. And the instruments are described specifically as follows.

Questionnaires. The questionnaire aims to collect the effective data for the research, which is widely used in education research. Here are two questionnaires: the pre-questionnaire and the post-questionnaire.

(1) The pre-questionnaire

Before the experiment, per-questionnaire is designed to get the first-hand information of students' English reading comprehension (see Appendix).

(2) The post-questionnaire

After 3 months' learning, students in the two groups are required to attend the post-questionnaire respectively in order to get a feedback of students' current situations (see Appendix).

Tests. Throughout the experimental research, there are two tests given to the subjects before and after reading, they are pre-test and post-test. Each test is a reading examination with the same standard criterion. The purpose of the pre-test is to master the current reading comprehension of the two group students. And the post-test aims to investigate the difference between the two groups after learning by different teaching methods.

(1) Pre-test

Before the experiment, the students of the two groups are required to take an English reading test to see their 
current English reading comprehension. In the test, the two group students are presented four reading materials. What they should do is to finish reading them and complete the exercises in 35 minutes. After finishing the test, the papers are all collected by the researcher in order to evaluate and analyze.

(2) Post-test

After 3 months' teaching experiment with different teaching methods, another English reading test will be required to the students of the two groups. Just like the per-text, they should finish the text in 35 minutes. After the test, 60 papers are returned and collected by the researcher to conduct analyzing in the following section.

Interview. This interview is used at the end of the experiment, that is to say, it will be done at last during the whole experiment. The main purpose of this interview is to find out after 3 months' reading training under the network environment whether the students can improve their English reading comprehension and change their reading habits.

In the interview, five students are chosen randomly from the experimental group. And the author conducts an interview with the five students individually, each student should answer three questions, and 5 minutes is allocated to each student.

Because interview is a kind of conversation so we can have a well master of the significance of learning under the network environment through face-to-face talking. In addition, because none of the questions is involved with personal affairs, there is no need for the interviewees to concern about the results of the interview.

\section{Results and Analysis}

\section{Results of Questionnaires}

Results of pre-questionnaire. At first, let us have an analysis of the pre-questionnaire which mainly consists of eight questions. The questions are designed to know students' (including the experimental group and the control group) attitude towards reading with the traditional teaching model, where the teacher is the center and controller of the class and the students only listen to the teacher passively. After the survey, we can get these statistics:

Table 1

Statistics of Both the Experimental Group and the Control Group

\begin{tabular}{llllll}
\hline & A (\%) & B (\%) & C (\%) & D (\%) & E (\%) \\
\hline 1 & 9 & 25 & 44 & 10 & 12 \\
2 & 15 & 35 & 30 & 15 & 10 \\
3 & 7 & 32 & 34 & 21 & 6 \\
4 & 27 & 20 & 18 & 11 & 12 \\
5 & 26 & 26 & 37 & 13 & 2 \\
6 & 12 & 31 & 42 & 10 & 1 \\
7 & 15 & 31 & 23 & 4 & 25 \\
\hline
\end{tabular}

From Table 1 we can get these conclusions: At first, most of the students' reading interests, reading time, reading amount, and speed are not so high. Second, most of the subjects do not realize that using reading strategies is helpful to their English reading, or, it can be said that their reading strategy is simplex. Third, few of the subjects have awareness of cooperative learning spirits.

Results of post-questionnaire. After 3 months, the same questionnaire was presented to the two groups. 
Let us take a look at the statistics (see Tables 2-3).

Table 2

The Statistics of the Control Group

\begin{tabular}{lllllc}
\hline & A (\%) & B (\%) & C (\%) & D (\%) & E (\%) \\
\hline 1 & 11 & 32 & 38 & 12 & 7 \\
2 & 18 & 32 & 30 & 15 & 5 \\
3 & 13 & 34 & 31 & 16 & 6 \\
4 & 21 & 48 & 28 & 26 & 9 \\
5 & 10 & 27 & 37 & 13 & 13 \\
6 & 17 & 32 & 35 & 14 & 2 \\
7 & 41 & 33 & 22 & 3 & 1 \\
8 & 2 & 39 & 30 & 38 & 18 \\
\hline
\end{tabular}

Table 3

The Statistics of the Experimental Group

\begin{tabular}{lllllc}
\hline & A (\%) & B (\%) & C (\%) & D (\%) & E (\%) \\
\hline 1 & 53 & 36 & 7 & 3 & 1 \\
2 & 19 & 38 & 32 & 9 & 2 \\
3 & 13 & 35 & 37 & 14 & 1 \\
4 & 15 & 25 & 11 & 49 & 0 \\
5 & 1 & 19 & 26 & 11 & 43 \\
6 & 22 & 36 & 31 & 10 & 1 \\
7 & 48 & 33 & 18 & 1 & 0 \\
8 & 0 & 49 & 33 & 21 & 47 \\
\hline
\end{tabular}

The responses to the pre-questionnaire and post-questionnaire have revealed that both groups changed their attitudes towards English reading and the students of the experimental group have a bigger change than the control group in some aspects. They began to show interest in English reading and willing to do activities through the Internet, which could be described in details as follows:

(1) Reading motivation. From the pre-questionnaire and the post-questionnaire of the control group, the result of Question 1 shows that lots of the students' reading interests are not high enough. While from the post-questionnaire, over half of the students in the experimental group hold the positive attitude, these tell us that many students' reading motivation can be improved under network learning.

(2) Reading speed and time. The results of Questions 2-3 show that learning with the traditional teaching model, most of students' reading time is limited and and their reading speed is not high. However, after 3 months' learning, the statistics show that more students' (in the experimental group) reading speed and autonomous reading are promoted.

(3) Reading strategies. From the pre-questionnaire and the post-questionnaire of the control group, the results of Questions 4-5 show the students are poor in the use of English reading strategy in the traditional reading class; however, from the post-questionnaire, the students of the experimental group began to use the Internet more and more frequently. It shows that most students are willing to use reading strategies after the reading teaching under network environment.

(4) The collaboration. From the pre-questionnaire and the post-questionnaire of the control group, the result 
of Question 6 shows that only a few of students have the cooperative awareness in the traditional English reading class. Some of them even do not have any experience for collaborative reading. But from the post-questionnaire of the experimental group, it can be clearly seen that the students began to communicate with others. From the above we can get conclusion that more students have the collaborative reading awareness under network environment.

(5) Experience of reading under the network. From the pre-questionnaire and the post-questionnaire of the control group, the results of Questions 7-8 show that a few of the students like to do English reading through Internet. However, from the post-questionnaire of the experimental group, the results show that a lot of students are benefited more or less by reading through network and it can be seen from Question 8 that many students spend more time on searching reading materials when they are online.

Summary of the two questionnaires. The experimental teaching lasts for 3 months, and the author made some research. From the analysis of the results of the pre-questionnaire and the post-questionnaire, the reading teaching model under network not only promote students' interest in learning but also improve teachers' teaching efficiency. At the same time, it also extends the student's reading vision and then improves their reading comprehension. After 3 months' learning, the students of the experimental group can use more reading learning strategies, which makes up for certain deficiencies in the traditional classroom teaching, thus, the model has practical and application value.

\section{Results of Tests}

To begin with, there is a test for the two groups. And after 3 months, another test was prepared for them. The tests' results can be shown in the following chart (see Table 4).

Table 4

The Results of the Two Tests During the Experiment

\begin{tabular}{lllll}
\hline & \multicolumn{2}{c}{ Pre-test } & \multicolumn{2}{c}{ Post-test } \\
\cline { 2 - 5 } & The experimental group & The control group & The experimental group & The control group \\
\hline Highest score & 38 & 38 & 40 & 40 \\
Lowest score & 16 & 16 & 18 & 16 \\
Average score & 27.93 & 27.93 & 32.47 & 28.27 \\
\hline
\end{tabular}

Comparing the scores of the tests, a comparative improve could be seen. In the pre-test, two groups have the same scores. However, after 3 months in the post-test, both groups have improved their reading abilities especially the experimental group.

In addition, it indicates that to teach English reading under the network environment does well to the students' reading comprehension. It both broadened the student's reading horizons and better improved their reading strategy after 3 months' learning. That is why the traditional methods of teaching are inferior to bear comparison.

\section{Results of Interview}

After 3 months' experiment, there was an interview. It was conducted with five randomly-chosen students in the experimental group mainly focusing on three questions such as "Compared with the traditional teaching model, what different things have you learned from the experiment?”, "What is your deepest impression on the 
present teaching model?”, “ Which aspects of the new teaching model do you think should be improved?”. During the interview, the interviewees' remarks are taken down carefully. And their opinions are summarized as follows:

(1) The network-based reading teaching is superior to the traditional one. According to the students of the experimental group, there is no need to put emphasis on word meanings, grammar, or the sentence structures reading under the network environment, it just focuses much on the use of the network, which cannot only improve students' reading interests, but also expand their reading visions, and then develop their reading comprehension.

(2) The deepest impression of network-based teaching. They think reading under the network environment can greatly arouse their learning interests. What is more, instead of following with teachers, they can read according to their own reading level and their own reading habits.

(3) Some suggestions. Frankly speaking, English reading teaching under the network environment still has some deficiencies. Such as the use of network requires higher profession skills for both teachers and students; controlling the whole reading process is difficult for teacher in a certain degree and so on. All of these problems should be considered seriously and finding practical ways to solve.

From the analysis of the results we can see that although reading under network environment has some shortcomings to some degree, it has its value of further application and practice.

\section{Conclusion}

With the good cooperation given by the students, the goal of the present research has generally achieved after the experiment.

(1) Different from traditional teaching method which is teacher-centered, Online Teaching Model can establish a real student-centered learning platform, on which students can choose what they like to read on their own minds under the network environment. Such environment can promote students' initiative, enthusiasm, and creativity, and ultimately achieve their effective learning result.

(2) Students' reading ability has improved. The reading computer software can provide the students with a variety of materials to read. In the process of reading with computer, students can interact with others frequently, get reading feedback immediately, correct their mistakes timely and adjust their reading strategy effectively. All these can improve students' reading comprehension.

Generally speaking, there is still a wide space for further teaching and learning practice under the network environment.

\section{References}

Blachowicz, C., \& Ogle, D. (2008). Reading comprehension strategies for independent learners (p. 80). New York \& London: The Guilford Press.

Carrel, P. L., Devine, J., \& Eskey, D. E. (2006). Interactive approaches to second language reading (p. 67). Oxford: Cambridge University Press.

GU, Y. G., Hall, C., \& Hall, E. (2007). Using the computer in ELT-Technology, practice and theory (p. 22). Beijing: Foreign Language Teaching and Research Press.

Levy, M. (2008). Research and technological innovation in CALL—RETRACTED. Innovation in Language Learning and Teaching, (3), 303-305. 
LIU, J. M. (2006). The application of a web-based reading instructional model among English majors in China (Master's thesis).

Capital Normal University, Beijing, China.

Nunan, D., \& LIN, L. (2008). Practical English language teaching (p. 71). Nanjing: Yi Lin Press.

Nuttal, C. (2002). Teaching reading skills in a foreign language (p. 12). Shanghai: Shanghai Foreign Language Education Press. QING, X. Q. (2009). Foreign language teaching questionnaire (p. 46). Beijing: Foreign Language Teaching and Research Press. ZHANG, M. J. (2008). A new network-based reading teaching model for English majors. Journal of Wu Yi College, 6, 80-82.

\section{Appendix: Questionnaire}

\section{Dear Classmates:}

This questionnaire aims to get the present situation of high school students in their English reading study and the frequency that high school students utilize internet in their study. It is done anonymously and there is no standard answer to each question. Thank you for your cooperation.

1. Do you think reading is interesting at present?
A. very interesting
B. interesting
C. just so so
D. not very interesting
E. not interesting

2. How long do you spend in English reading everyday?
A. over 3 hours
B. 2 to 3 hours
C. 1 to 2 hours
D. about an hour
E. less than half an hour

3. When there is no more than $2 \%$ to $3 \%$ new words in a passage, how many words can you read in one minute?
A. more than 120 words
B. 90-120 words
C.70-90 words
D. 50-70 words
E. less than 50 words

4. What would you do when you encounter some unknown words or phrases in reading? (Multi-choice)
A. guess
B. look up a dictionary
C. ask others
D. search on the internet
E. ignore

5. What other ways would you take for English reading except for the task assigned by the teacher?
A. None
B. Through the recommendation of others
C. To the Library
D. By English newspaper or journal
E. Through internet

6. Would you communicate or work with your classmates in the process of reading or after the reading?
A. Every time
B. Often
C. Sometimes
D. Once in a while
E. Never

7. Do you think reading strategies or skills would be helpful for your English reading?
A. Of great help
B. Of some help
C. Sometimes it helps
D. Of little help
E. Of no help

8. What would you do when you surf on the internet? (Multi-choice)
A. Do nothing
B.Search for information
C. Read news
D. Chat or play
E. English reading 